\title{
Anterior Cusp of the Pulmonary Valve
}

National Cancer Institute

\section{Source}

National Cancer Institute. Anterior Cusp of the Pulmonary Valve. NCI Thesaurus. Code C127673.

The cusp of the pulmonic valve that has no attachment to the cardiac septum. 